\title{
Zinc Fuming from Lead Blast Furnace Slag
}

\author{
R. G. Reddy ${ }^{1^{*}}$, V. L. Prabhu ${ }^{2}$ and D. Mantha ${ }^{3}$ \\ 'ACIPCO Professor, ${ }^{2}$ Graduate Student, and ${ }^{3}$ Researc'h Associate \\ Department of Metallurgical and Materials Engineering \\ P. O. Box 870202, The University of Alabama \\ Tuscaloosa, AL 35487-0202, U. S. A. \\ e-mail: rreddy@coe.eng.ua.edu
}

(Received March 3,2003)

\begin{abstract}
Laboratory studies have been carried out to recover zinc from an industrial lead blast furnace slag using carbon as an external reducing agent. Experiments were conducted at $1573 \mathrm{~K}$ with and without carbon addition, and with different flow rates of argon or air as stirring gas. Results show that rate of zinc fuming increases with increase in carbon content of the melt and flow rate of the stirring gas (air or argon). In melts containing no carbon the results suggest that $\mathrm{ZnO}$ reduction took place by the diffusion of $\mathrm{Fe}^{+2}$ ions in the melt. Chemical reaction at the gas-slag interface was the rate controlling step in melts containing varying amounts of carbon. The type of stirring gas (air or argon) or the flow rate did not influence the reaction mechanism. Results from this investigation agree favorably with those reported in the literature on the zinc fuming process.
\end{abstract}

\section{INTRODUCTION}

Processing of slag is an important unit operation in the extraction of non-ferrous metals. Slag treatment is important in the flash-smelting processes for lead concentrates, smelting of tin, and in the extraction of copper and nickel from high grade mattes. Traditionally slag processing has only been a secondary operation and not a part of the primary extraction process. Slag fuming is normally practiced to recover zinc from lead blast furnace slags.

The slag fuming process has become operative since 1930s to recover zinc from lead blast furnace slag. The first slag fuming operation was commenced by the Anaconda Copper Mining Co., at East Helena, Montana in 1927. Since then the slag fuming operation was accomplished with success by the use of a reducing agent in the form of carbon/coal for the extraction of volatile elements like zinc. It is a reductive treatment of molten slag to recover zinc from dissolved zinc oxide. Slag fuming is a batch process in which a reducing mixture of air and pulverized coal is injected into the molten slag. The coal-air mixture reduced the zinc oxide from the slag to metallic zinc vapor. The furnace is usually operated between the temperatures of $1423-1573 \mathrm{~K}$. Carbon in the form of coal/graphite acts as both a reductant and as fuel to maintain bath temperature during the endothermic reduction process. The partition of coal between the slag, combustion and bypass is dependent on factors such as bath depth and injection pressure.

The reactions involved in the recovery of zinc from the lead blast furnace slag can be described as follows:

$$
\mathrm{ZnO}(\mathrm{I})+\mathrm{C}(\mathrm{s})=\mathrm{Zn}(\mathrm{g})+\mathrm{CO}(\mathrm{g})
$$

The above reaction takes place in two steps via $\mathrm{CO}$ gas phase as:

\footnotetext{
" Corresponding Author
} 


$$
\begin{aligned}
& \mathrm{ZnO}(\mathrm{l})+\mathrm{CO}(\mathrm{g})=\mathrm{Zn}(\mathrm{g})+\mathrm{CO}_{2}(\mathrm{~g}) \\
& \mathrm{C}(\mathrm{s})+\mathrm{CO}_{2}(\mathrm{~g})=2 \mathrm{CO}(\mathrm{g})
\end{aligned}
$$

All the above reactions are endothermic and the heat necessary for the reactions is generated by the combustion of coal in the bath. Lead blast furnace slags contain about $11-18 \mathrm{wt} \%$ zinc oxide, and other volatile species like lead and tin in the form of oxides. The liberated zinc vapor gets oxidized when it comes in contact with air above the bath. The products pass via a cooling system to a bag house in which the zinc oxide is collected along with lead and tin, which are also volatile and pass along with zinc oxide to the bag house.

The fuming furnace is rectangular in shape and has mild steel water jackets. Tuyeres are provided in a row near the bottom along each side of the furnace through which air and coal are introduced into the furnace. The charge normally consists of liquid lead blast furnace slag, although skulls from ladles and crushed slag can also be charged directly into the furnace, provided the furnace contains enough liquid to prevent formation of a mound at the bottom.

Selective reduction of zinc oxide over iron oxide takes place at temperatures above $1523 \mathrm{~K}$ since the thermodynamic stability of $\mathrm{FeO}$ is greater than that of $\mathrm{ZnO}$ above this temperature. Hence it is possible to preferentially reduce $\mathrm{ZnO}$ to $\mathrm{Zn}$ leaving $\mathrm{FeO}$ in the slag phase. The advantages of working at higher temperatures, apart from the above mentioned reason, are as follows: since less iron is reduced, less power would be required corresponding to less reductant usage resulting in less $\mathrm{CO}$ generation which would enable a smaller gas handling system for the reduction experiments.

Reduction of $\mathrm{ZnO}$ also takes place by $\mathrm{FeO}$ present in the slag at the operating temperature according to the following reaction,

$$
2 \mathrm{FeO}(\mathrm{I})+\mathrm{ZnO}(\mathrm{l})=\mathrm{Zn}(\mathrm{g})+\mathrm{Fe}_{2} \mathrm{O}_{3}(\mathrm{I})
$$

The reactions are believed to take place at the slag/gas interface in contact with the coke/graphite particles. It is possible that the concentrations of $\mathrm{CO}_{2}$ and $\mathrm{Fe}_{2} \mathrm{O}_{3}$ will increase with the progress of the reaction. However, due to the highly reducing atmosphere in the smelting furnace, the following reaction also takes place almost instantaneously.

$$
\mathrm{Fe}_{2} \mathrm{O}_{3}(\mathrm{l})+\mathrm{CO}(\mathrm{g})=2 \mathrm{FeO}(\mathrm{l})+\mathrm{CO}_{2}(\mathrm{~g})
$$

Reaction (5) ensures high activity of $\mathrm{FeO}$ in the slag by reduction of the ferric oxide by $\mathrm{CO}$ and reaction (3) ensures that the partial pressure of $\mathrm{CO}$ is high in order to enable reaction (1) to proceed to the right. For obvious reasons the presence of a reducing agent like graphite would greatly influence the extent to which the above reactions take place.

Temperature plays an obvious role in improving the reaction kinetics of any heterogeneous reaction system. Higher temperatures lead to low viscosity of the slag melt, which enables a well stirred slag in the furnace. It also ensures faster diffusion rates of the reacting species $\left(\mathrm{Zn}^{2+}, \mathrm{Fe}^{2+}, \mathrm{Fe}^{3+}\right)$ in the melt. A high smelting temperature is necessary to maintain the gas temperature to the condenser inlet at above $1000^{\circ} \mathrm{C}$ in order to prevent the zinc vapor from reacting with $\mathrm{CO}_{2}$ to form zinc oxide below $1000^{\circ} \mathrm{C}$. However, too high a temperature will cause furnace refractory erosion by thermal degradation and slag attack. Moreover, the overall energy requirements will also increase with higher temperatures. Hence, keeping these limitations in mind, the experiments in this investigation were conducted at an optimum temperature of $1573 \mathrm{~K}$.

In the present investigation, experiments were conducted at $1573 \mathrm{~K}$ on an industrial lead blast furnace slag using argon/air for stirring the slag melt at different flow rates and with/without graphite as an external reducing agent to study the zinc fuming kinetics, and an attempt was made to determine the rate determining step in the reduction process.

\section{LITERATURE REVIEW}

An excellent review of the early experiments on zinc fuming has been made by Courtney /1/ who described blast furnace, reverberatory furnace, and converter methods of fuming zinc from slag. Earlier investigations used compressed air without any reducing agent to 
accomplish the zinc oxide reduction from the lead blast furnace slag.

Although commercial slag fuming had commenced, no great attempt was made in the first half of the century to study the chemistry of the process. Bell et al. 12/ published the first useful model of the slag fuming process with an assumption that, at any instance, the zinc oxide in the slag and the reducing gas (CO) reach a state of equilibrium according to the reaction (2). From the experimental data obtained, Bell et al. /2/ calculated the activity of zinc oxide as a function of concentration of zinc oxide in the slag and used this as a basis for the prediction of the furnace performance.

Kellogg /3/ developed the first computer model of the slag fuming process. He assumed that the gas-slag equilibrium condition postulated by Bell et al. /2/ contributed to the rate control. In his study, one of the important factors discovered was the transfer of sulfur between the gas and slag. Although the amount of sulfur in the gas phase was small, it was found to be important for a quantitative description of the behavior of zinc and lead. Additionally, the method assumes stepwise equilibrium during each microstep ( 0.1 minute in a 90 minute period) facilitating the use of a computer in the calculations.

Kellogg /4/ earlier carried out experiments by stopping the coal supply for a five minute period but maintaining the same air rate.

Quarm $15 /$ found that appreciable zinc fumed without any external reducing agent by just mechanically disturbing the slag. Based on this observation, he concluded that a reducing species present in the slag reduced the zinc oxide. The only reducing species in the slag present in suitable quantity is $\mathrm{FeO}$ and he concluded that $\mathrm{FeO}$ plays an important role in the slag fuming process.

None of the above theories have been able to explain the slag fuming process convincingly. There are two aspects that need attention, firstly the existence of equilibrium of the zinc oxide reduction and secondly the need of an external reducing agent. In the present investigation an attempt has been made to understand the mechanism of $\mathrm{ZnO}$ reduction with and without an external reducing agent by carrying out controlled laboratory experiments on a lead blast furnace slag.

\section{EXPERIMENTAL}

Experiments were performed to study the main reactions involved in the reduction of zinc oxide from lead blast furnace slags both in the absence and presence of an external reducing agent. An attempt was made to determine the possible rate controlling mechanism of the reduction process based on the results of this investigation.

Industrial lead blast furnace slag was used in the present experiments. The composition of the slag is given in Table 1. Experiments were performed in recrystallized alumina crucibles of $100 \mathrm{ml}$ capacity. The crucible was contained in a thick walled crucible holder with a packing of alumina beads between the crucible and the holder. Known amounts of precrushed slag (100 g) and graphite (wherever applicable) were mixed together and packed in the crucible. The crucible assembly was then introduced into a vertical tube furnace. Figure 1 shows the schematic of the experimental setup. The temperature of the furnace was slowly raised to the operating temperature of $1573 \mathrm{~K}$. The slag took approximately 20 minutes to reach molten state at $1573 \mathrm{~K}$. The melt was stirred by air or argon depending on the experimental sequence. The stirring

Table 1

Initial composition of lead blast furnace slag used in this investigation

\begin{tabular}{|c|c|}
\hline Component & Amount, wt \% \\
\hline $\mathrm{ZnO}$ & 12.60 \\
\hline $\mathrm{PbO}$ & 0.90 \\
\hline $\mathrm{SnO}$ & 1.50 \\
\hline $\mathrm{FeO}$ & 29.7 \\
\hline $\mathrm{CaO}$ & 20.4 \\
\hline $\mathrm{Al}_{2} \mathrm{O}_{3}$ & 5.67 \\
\hline $\mathrm{SiO}_{2}$ & 28.3 \\
\hline $\mathrm{MgO}$ & 0.92 \\
\hline
\end{tabular}




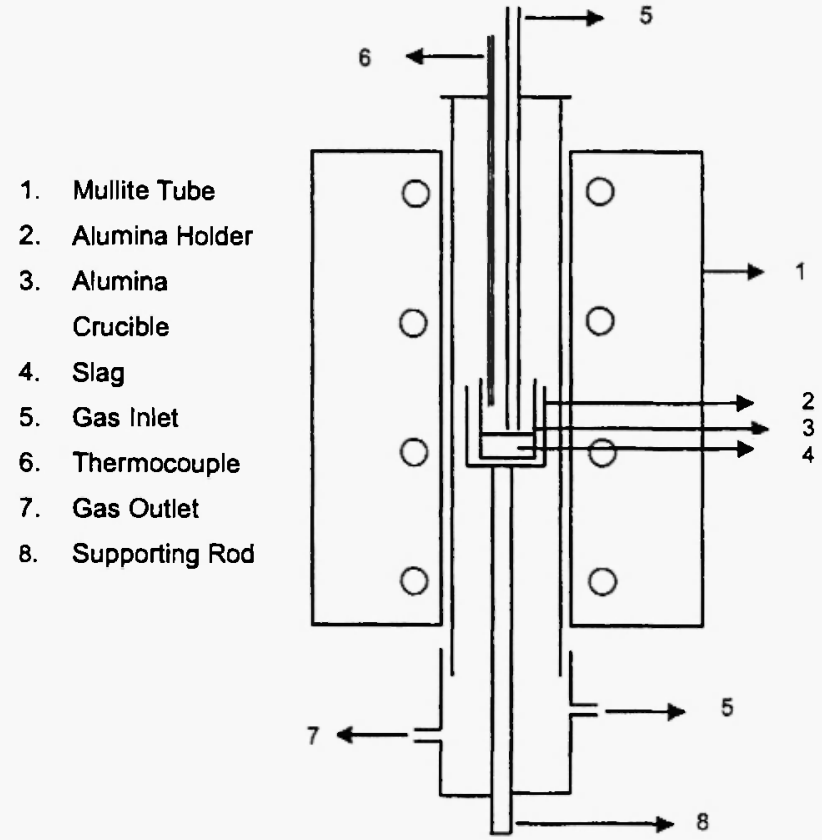

Fig. 1: Schematic diagram of the experimental setup.

gas was introduced into the slag through a silica tube (4 $\mathrm{mm} \mathrm{ID} \mathrm{and} 6 \mathrm{~mm} \mathrm{OD)}$ ). The slag samples were taken at regular intervals up to 100 minutes of the experiment by introducing a stainless steel rod into the molten slag by stirring and withdrawing rapidly. All the experiments were conducted at $1573 \mathrm{~K}$. Experiments were carried out without carbon and with varying amounts of carbon ( 5 wt $\%$ and 12 wt \%) in the melt. In two of the experiments no external gas was introduced for stirring the melt while in the others either argon or air was introduced at different flow rates. Table 2 lists the different experimental conditions used to study the slag fuming process. The influence of various parameters such as addition of carbon, type of gas used for stirring and the flow rate of the stirring gas, on the rate of $\mathrm{ZnO}$ reduction was studied. Based on the results obtained in this investigation an attempt was made to determine the probable mechanism of $\mathrm{ZnO}$ reduction in the lead blast furnace slag.

\section{Slag Analysis}

The slag samples were analyzed by Atomic Absorption Spectrophotometer for zinc, lead and total
Table 2

The various experimental conditions studied in the present investigation

\begin{tabular}{|c|c|c|}
\hline $\begin{array}{c}\text { Carbon content, } \\
\text { wt } \%\end{array}$ & $\begin{array}{c}\text { Type of } \\
\text { stirring gas }\end{array}$ & $\begin{array}{c}\text { Flow rate, } \\
\text { cc/min }\end{array}$ \\
\hline 0 & - & - \\
\hline 0 & Argon & 400 \\
\hline 0 & Air & 400 \\
\hline 5 & - & - \\
\hline 5 & Argon & 169 \\
\hline 5 & Argon & 300 \\
\hline 5 & Air & 375 \\
\hline 12 & Air & 650 \\
\hline
\end{tabular}

iron. The amount of ferrous iron $\left(\mathrm{Fe}^{+2}\right)$ in the slag was determined by titration using $\mathrm{K}_{2} \mathrm{Cr}_{2} \mathrm{O}_{7}$. The ferric iron $\left(\mathrm{Fe}^{3+}\right)$ was calculated by subtracting the amount of ferrous iron from the total iron content of the sample assuming no precipitation of metallic iron.

\section{RESULTS AND DISCUSSION}

Eight experiments were conducted at $1573 \mathrm{~K}$ under different conditions as mentioned earlier. The results of the experiments were analyzed with respect to the influence of several variables such as carbon content of the melt, type of gas used for stirring the melt and flow rate of the stirring gas, on the reduction behavior of $\mathrm{ZnO}$ from the lead blast furnace slag.

\section{A. Effect of Carbon Addition without Stirring}

Figure 2 shows the effect of carbon on the rate of $\mathrm{ZnO}$ reduction from the $\mathrm{Pb}$ blast furnace slag at $1573 \mathrm{~K}$ without stirring the melt. The results clearly indicate that carbon addition improves the rate of $\mathrm{ZnO}$ by direct reduction. The results of this study follow those reported by Richards et al. /6/. They made industrial measurements of the zinc fuming process and studied the kinetics of reduction of $\mathrm{ZnO}$ by using coal as a reducing agent. 


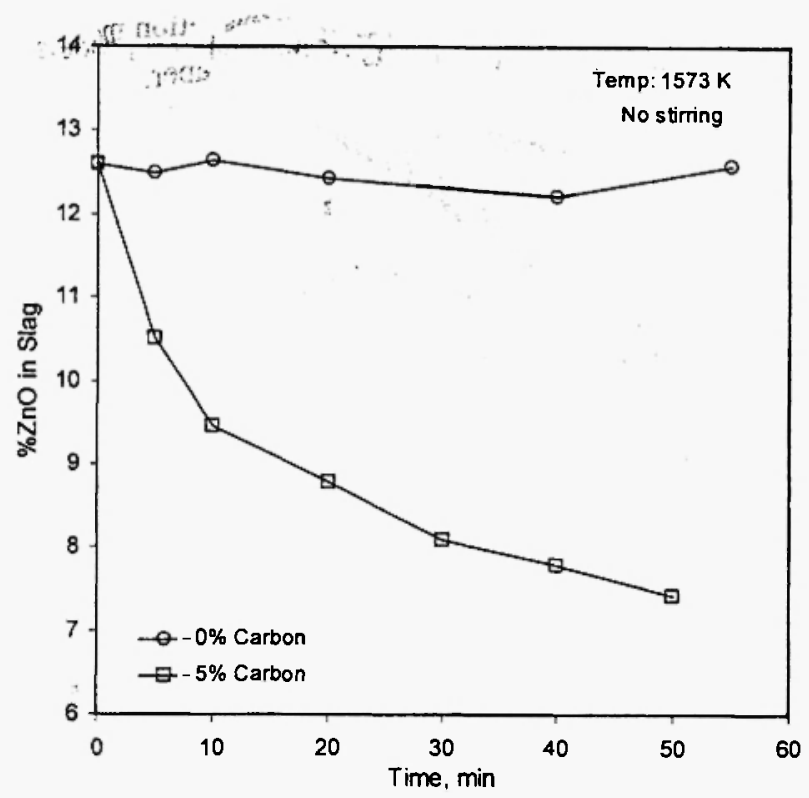

Fig. 2: Effect of carbon on the rate of reduction of $\mathrm{ZnO}$ from lead blast furnace slag at $1573 \mathrm{~K}$.

\section{B. Effect of Gas Stirring without Carbon Addition}

Figure 3 shows the effect of stirring the slag melt on the rate of $\mathrm{ZnO}$ reduction at $1573 \mathrm{~K}$ without any external reducing agent. Stirring the slag melt improved the rate of $\mathrm{ZnO}$ reduction. Stirring by air slightly improved the reduction of $\mathrm{ZnO}$ in comparison to argon. Although there was no external reducing agent in the melt, reduction of $\mathrm{ZnO}$ took place by $\mathrm{FeO}$ present in the slag as given by equation (4). Slightly better kinetics observed in case of air stirring could be due to its influence on the $\mathrm{Fe}^{+2} / \mathrm{Fe}^{+3}$ (i.e., $\mathrm{FeO} / \mathrm{Fe}_{2} \mathrm{O}_{3}$ ) ratio in the melt. Deneys et al. $/ 7 /$ reported an experimental study of zinc fuming from lead blast furnace slags using a twoslag mixture. Their results indicate that in the absence of any carbonaceous reducing agent the reduction of $\mathrm{ZnO}$ took place by $\mathrm{FeO}$ present in the slag. Figure 4 shows the change in the ratio $\left(\mathrm{FeO} / \mathrm{Fe}_{2} \mathrm{O}_{3}\right)$ in slag with the progress of the reaction for two experiments containing no external reducing agent. This plot shows that the ratio $\left(\mathrm{FeO} / \mathrm{Fe}_{2} \mathrm{O}_{3}\right)$ decreases with time in both the cases of argon and air stirring. In case of air stirring the slope of the curve is slightly larger. The $\mathrm{Fe}^{+3}$ content in the melt increases due to the reduction of $\mathrm{ZnO}$ given by equation (4) thereby the ratio $\left(\mathrm{FeO} / \mathrm{Fe}_{2} \mathrm{O}_{3}\right)$ decreases

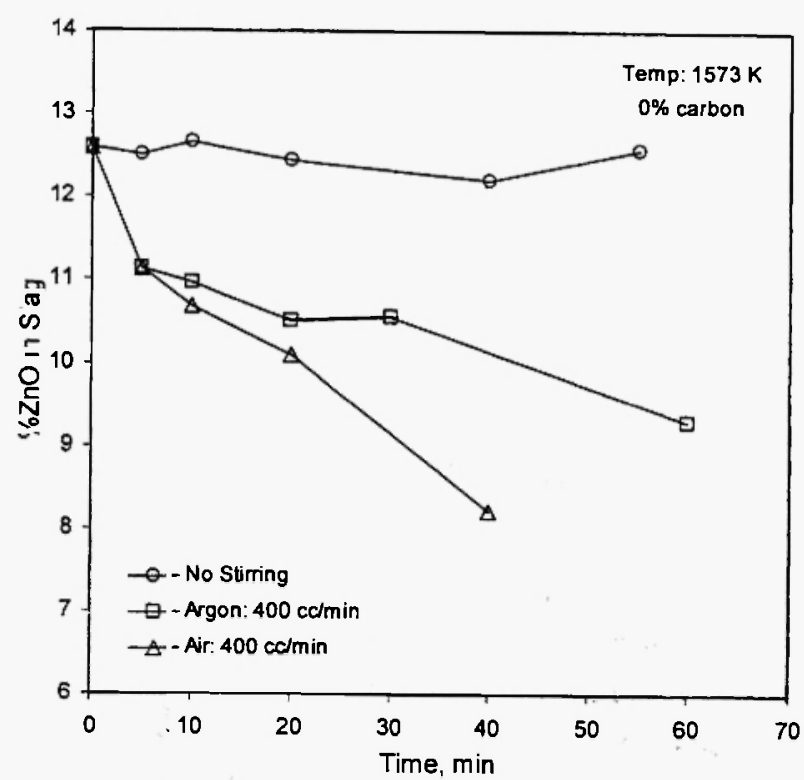

Fig. 3: Effect of gas stirring on the rate of $\mathrm{ZnO}$ reduction at $1573 \mathrm{~K}$ without any external reducing agent in the melt.

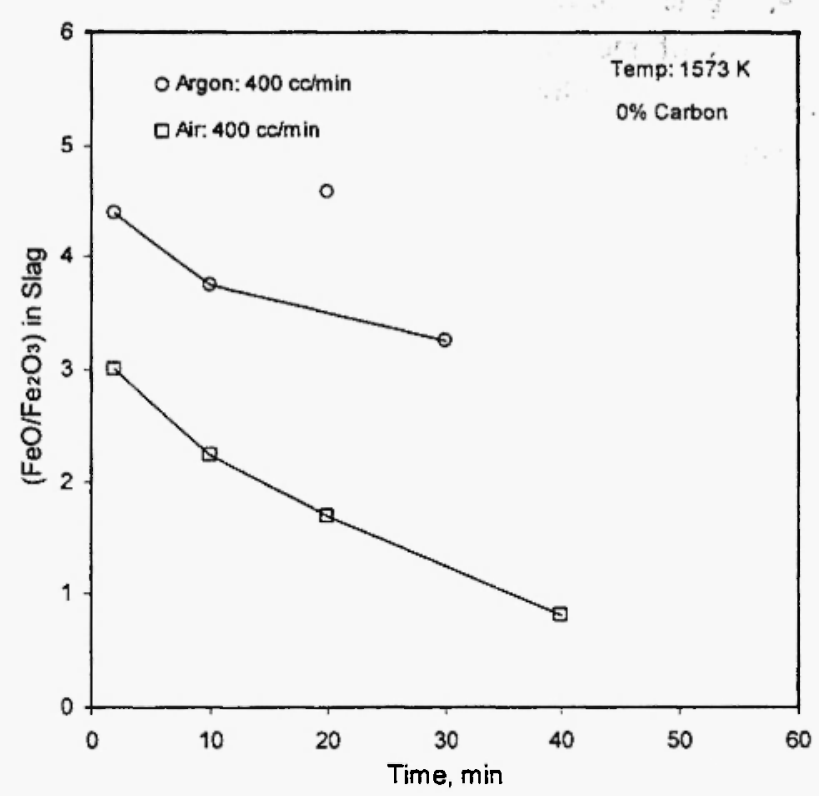

Fig. 4: Effect of the type of gas used for stirring the melt on the ratio of $\left(\mathrm{FeO} / \mathrm{Fe}_{2} \mathrm{O}_{3}\right)$ in the slag at $1573 \mathrm{~K}$ containing no carbon in the melt.

with the progress of the reaction. However, in the case of air stirring, oxidation of $\mathrm{Fe}^{+2}$ to $\mathrm{Fe}^{+3}$ may be partly due to the oxygen present in air and partly due to the reduction of $\mathrm{ZnO}$ in the melt. Hence, a greater change in 
the ratio could be expected in this case. Our results confirm the results obtained by Rankin and Wright /8/ who studied the reduction kinetics of $\mathrm{ZnO}$ from lead blast furnace slags using an iron-carbon alloy bath. They reported that the reduction of $\mathrm{ZnO}$ was influenced by the diffusion of $\mathrm{Fe}^{+3}$ ions the melts containing no iron-carbon alloy bath.

\section{Effect of Argon Stirring with Fixed Carbon Addition}

The effect of flow rate of argon on the rate of $\mathrm{ZnO}$ reduction at a fixed amount ( $5 \mathrm{wt} \%$ ) of carbon in the slag is depicted in Fig. 5. In the absence of melt stirring, $\mathrm{ZnO}$ reduction took place by carbon present in the melt. When the melt was stirred by argon at a flow rate of 169 $\mathrm{cc} / \mathrm{min}$, the reduction rate increased compared that observed in an unstirred melt. Higher flow rate of argon led to further improvement in the reduction rate of $\mathrm{ZnO}$, yielding less than $1 \mathrm{wt} \% \mathrm{ZnO}$ in the slag after 50 minutes of the experiment. Reduction of $\mathrm{ZnO}$ takes place essentially by the indirect reaction via $\mathrm{CO}$ at the slag/gas interface but stirring of the melt by a nonreacting gas (argon) led to the improved reaction kinetics. The kinetics of reduction was essentially due to the chemical reaction at the slag/gas interface and this

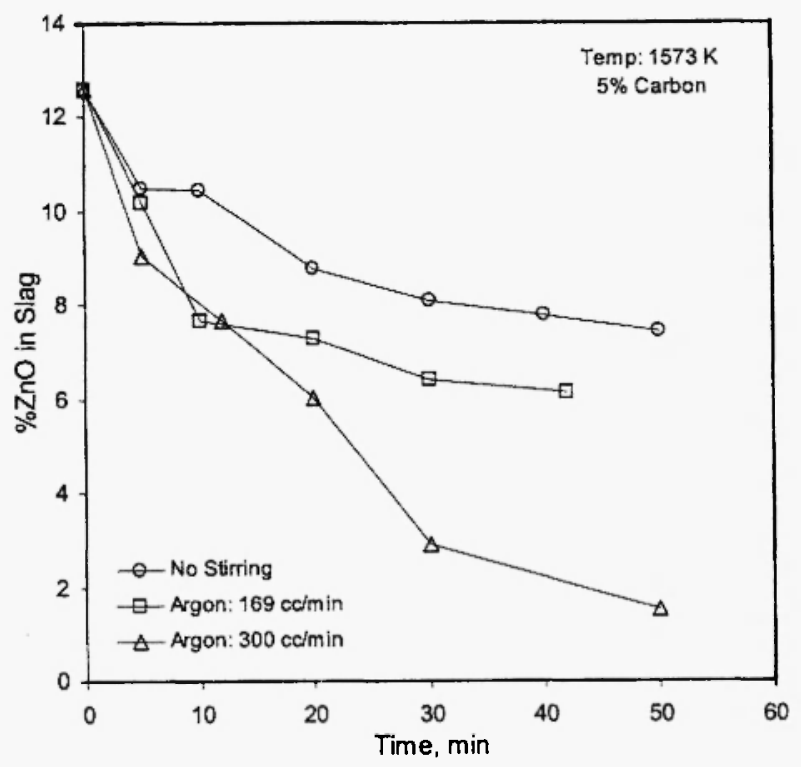

Fig. 5: Effect of flow rate of argon on the reduction of $\mathrm{ZnO}$ at $1573 \mathrm{~K}$ with $5 \mathrm{wt} \%$ carbon in the melt. fact was confirmed by the results of the reaction models developed in the following section of this paper.

\section{Effect of Flow Rate of Air}

Figure 6 shows the effect of flow rate of air on the reduction of $\mathrm{ZnO}$ in the slag with varying amounts of carbon in the melt. In the absence of carbon, reduction of $\mathrm{ZnO}$ is exclusively due to $\mathrm{FeO}$ present in the slag. Addition of carbon (5 wt \%) improves the reduction drastically due to the chemical reaction at the slag/gas reaction. However, increase in carbon content of the melt and flow rate of air did not show any appreciable improvement in the rate of $\mathrm{ZnO}$ reduction. This figure essentially determines the limit of external reducing agent on the zinc fuming process. Any amount of carbon higher than about $5 \%$ does not improve the reaction kinetics even with higher flow rate of the gas used for stirring the melt.

It appears from the results of this investigation that the reduction of $\mathrm{ZnO}$ took place both by chemical reaction at the slag/gas interface and also due to the diffusion of species such as $\mathrm{Zn}^{+2}$ or $\mathrm{Fe}^{+2}$ in the slag melt. In order to interpret the experimental results in terms of the possible reaction mechanisms, theoretical models both for chemical reaction and diffusion have

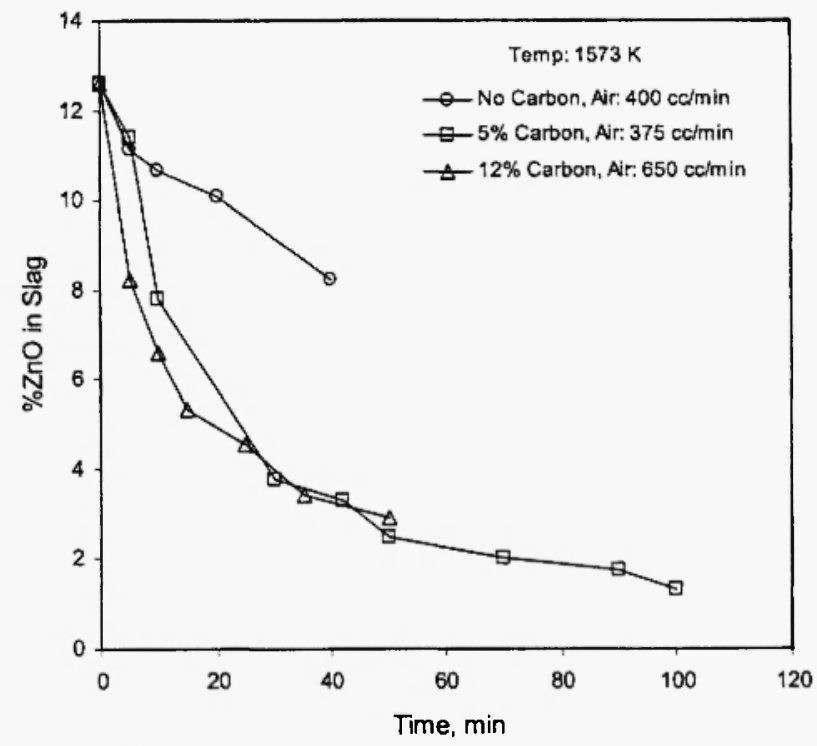

Fig. 6: Effect of flow rate of air on $\mathrm{ZnO}$ reduction at $1573 \mathrm{~K}$ with varying amounts of carbon in the melt. 
been developed. An attempt has been made to estimate the possible mechanism of reduction based on these models. Both the models are described briefly in the following sections.

\section{REACTION MODELS}

The heterogeneous system in this investigation involves an interaction between two phases, slag phase and the gas phase. Reaction at the slag/gas interface is primarily due to $\mathrm{CO}$ generated by the Boudouard reaction. The reaction kinetics in the present system could involve a number of rate limiting steps, which include transport of the reactants within the slag phase, chemical reaction at the slag/gas interface and nucleation of the product phase at the reaction interface. However, it appears from the present results that for the reduction of $\mathrm{ZnO}$ alone there could be only two possible mechanisms, namely, chemical reaction at the slag/gas interface and diffusion of species $\left(\mathrm{Zn}^{+2}\right.$ or $\left.\mathrm{Fe}^{+2}\right)$ in the melt.

\section{A. Chemical Reaction Model}

Reduction of zinc oxide from the lead blast furnace slag by carbon takes place at the slag/gas interface via the Boudouard reaction given by the following equation,

$$
\mathrm{ZnO}(\mathrm{sl})+\mathrm{CO}(\mathrm{g})=\mathrm{Zn}(\mathrm{g})+\mathrm{CO}_{2}(\mathrm{~g})
$$

Assuming first order kinetics with respect to the reactant species $(\mathrm{ZnO})$, the rate of reduction reaction (6) is given by,

$$
-\frac{\mathrm{d} \% \mathrm{ZnO}}{\mathrm{dt}}=\mathrm{k}_{1} . \% \mathrm{ZnO}(\mathrm{sl})-\mathrm{k}_{2} . \% \mathrm{Zn}(\mathrm{g})
$$

where $k_{1}$ and $k_{2}$ are the forward and backward reaction rate constants and the symbols in brackets (sl) and (g) refer to the slag and the gas phases respectively. At steady state, the rates of the forward and backward reactions are equal. Hence we have the following relations,

$$
\mathrm{k}_{1} . \% \mathrm{ZnO}^{\mathrm{e}}(\mathrm{sl})=\mathrm{k}_{2} . \% \mathrm{Zn}^{\mathrm{e}}(\mathrm{g})
$$

where the superscript ' $e$ ' refers to the equilibrium steady state concentration. Mass balance for zinc in the system yields the following relation,

$$
\mathrm{W}_{\mathrm{m}} \cdot \% \mathrm{Zn}^{\mathrm{t}}=\mathrm{f} \cdot \mathrm{W}_{\mathrm{sl}} \cdot\left(\% \mathrm{ZnO}^{\mathrm{i}}-\% \mathrm{ZnO}^{\mathrm{t}}\right)
$$

where $W_{m}, W_{s l}$ and ' $f$ ' are the weight of the metal (in this case condensed zinc vapor), weight of the slag, and ratio of atomic weight of $\mathrm{Zn}$ to the molecular weight of $\mathrm{ZnO}$ and the superscripts ' $\mathrm{i}$ ' and ' $\mathrm{t}$ ' refer to the initial concentration and concentration at any time respectively. Substituting the relations of $k_{2}$ and wt \% $\mathrm{Zn}(\mathrm{g})$ into equation (7) yields equation (10) given by,

$$
\begin{aligned}
& -\frac{\mathrm{d}^{2} \mathrm{ZnO}^{\mathrm{t}}}{\mathrm{dt}}= \\
& \mathrm{k}_{1} \cdot \frac{\% \mathrm{ZnO}^{\prime}}{\% \mathrm{ZnO}^{\prime}-\% \mathrm{ZnO}^{\mathrm{e}}} \cdot\left(\% \mathrm{ZnO}^{\mathrm{t}}-\% \mathrm{Zn}{ }^{\mathrm{e}}\right)
\end{aligned}
$$

where $\% \mathrm{ZnO}^{\prime}, \% \mathrm{ZnO}^{\prime}$, and $\% \mathrm{ZnO}^{\mathrm{e}}$ correspond to initial amount of zinc oxide, the amount present at any time ' $t$ ' and the equilibrium content of zinc oxide, all given in wt\%. Integration of equation (10) between the limits of time ' 0 ' to ' $t$ ' yields the rate constant $k_{1}$ for the reduction of zinc oxide controlled by the chemical reaction at the slag/gas interface which is given by,

$$
\begin{aligned}
& -\ln \left(\frac{\% \mathrm{ZnO}^{\mathrm{t}}-\% \mathrm{ZnO}^{\mathrm{e}}}{\% \mathrm{ZnO}^{\mathrm{i}}-\% \mathrm{ZnO} \mathrm{O}^{\mathrm{e}}}\right)= \\
& \mathrm{k}_{1} \cdot\left(\frac{\% \mathrm{ZnO}}{\% \mathrm{ZnO} \mathrm{O}^{\mathrm{i}}-\% \mathrm{ZnO}^{\mathrm{e}}}\right) \cdot \mathrm{t}
\end{aligned}
$$

Plotting the left hand side term as a function of time ' $t$ ' yields the rate constant for the chemical reaction controlled reduction of $\mathrm{ZnO}$ at a given temperature.

\section{B. Diffusion Model}

The derivation of a theoretical expression for the diffusion controlled model for the reduction of $\mathrm{ZnO}$ is done as follows: The diffusion of $\mathrm{ZnO}$ from the bulk of 
the slag phase to the slag/gas interface is given by equation (12).

$$
\mathrm{i}_{\mathrm{ZnO}}=-\mathrm{k}_{\mathrm{m}} \cdot\left(\mathrm{C}_{\mathrm{ZnO}}^{b}-\mathrm{C}_{\mathrm{ZnO}}^{\mathrm{i}}\right)
$$

where $J_{\mathrm{ZnO}}$ is the flux of $\mathrm{ZnO}, \mathrm{k}_{\mathrm{m}}$ is the mass transfer coefficient of $\mathrm{ZnO}$ in the slag phase, $\mathrm{C}_{\mathrm{ZnO}}^{\mathrm{b}}$ and $\mathrm{C}_{\mathrm{ZnO}}^{\mathrm{i}}$ are the concentrations of $\mathrm{ZnO}$ in the bulk melt and at the slag/gas interface respectively. If the reaction was controlled by the mass transport of $\mathrm{ZnO}$ through the slag phase, the chemical reaction at the slag/gas interface would be fast enough so that $\mathrm{C}_{\mathrm{ZnO}}^{\prime} \quad 0$.

Converting the concentration terms of the species into wt. pct. scale, we have

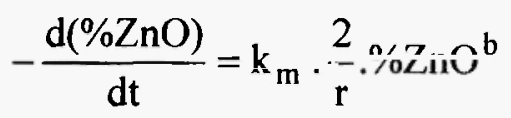

where ' $r$ ' is the radius of the cylindrical crucible, and $\% \mathrm{ZnO}^{\mathrm{b}}$ is the $\mathrm{wt} \%$ of $\mathrm{ZnO}$ in the bulk slag.

Integrating equation (13) within the limits of ' 0 ' and ' $t$ ' we get,

$$
-\ln \left(\frac{\% \mathrm{ZnO}^{\mathrm{t}}}{\% \mathrm{ZnO}}\right)=\frac{2}{\mathrm{r}} \cdot \mathrm{k}_{\mathrm{m}} \cdot \mathrm{t}
$$

where $\% \mathrm{ZnO}^{t}$ and $\% \mathrm{ZnO}^{t}$ are the amounts of $\mathrm{ZnO}$ given in $w t \%$ at any time ' $t$ ' and at the slag/gas interface respectively. Plotting the left hand side term of equation (14) as a function of time yields the mass transfer coefficient $\left(\mathrm{k}_{\mathrm{m}}\right)$ of $\mathrm{ZnO}$ for the diffusion controlled reaction at a given temperature. The rate controlling mechanism could be assessed by the linear fit of the experimental data to the model equations developed for the two proposed mechanisms. Although the expression for diffusion controlled model was derived for $\mathrm{ZnO}$, the equation can be used to represent the diffusion phenomenon of any other species such as $\mathrm{Fe}^{+2}$ or $\mathrm{Zn}^{2}$ in the melt.

Figure 7 shows the plot of the diffusion controlled model (left hand side term of equation (14)) for the $\mathrm{Fe}^{+2}$ ions in the slag melt as a function of time for the experiment conducted with no carbon in the melt and

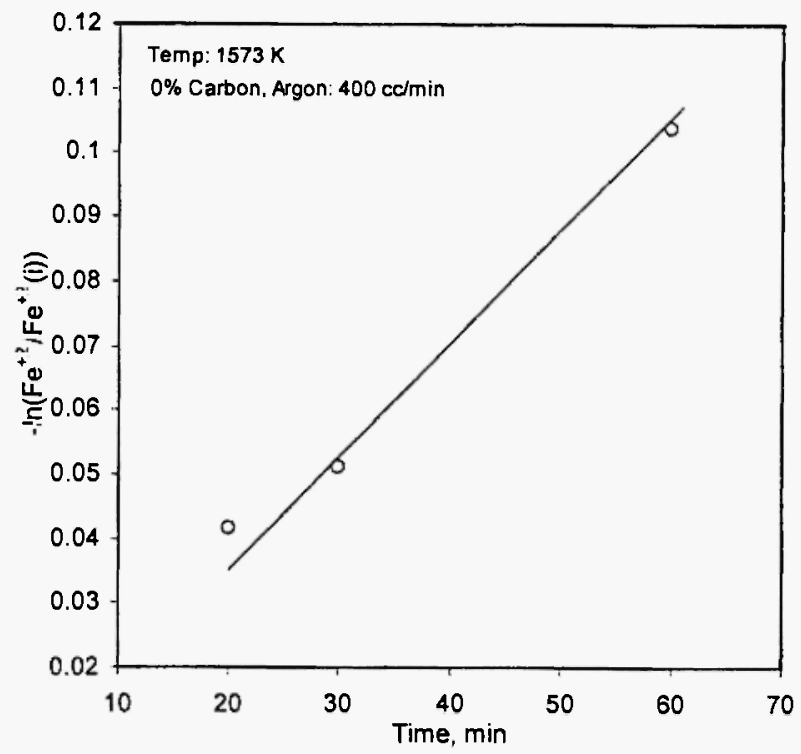

Fig. 7: Diffusion controlled model for $\mathrm{ZnO}$ reduction in melts containing $0 \%$ carbon and argon as the stirring gas at a flow rate of $400 \mathrm{cc} / \mathrm{min}$.

with argon flow rate of $400 \mathrm{cc} / \mathrm{min}$. The linearity of the plot indicates that the reduction of $\mathrm{ZnO}$ was controlled by diffusion of $\mathrm{Fe}^{+2}$ ions in the slag. Figure 8 shows a similar plot of diffusion controlled model (equation (14)) for the experiment conducted with air at a flow

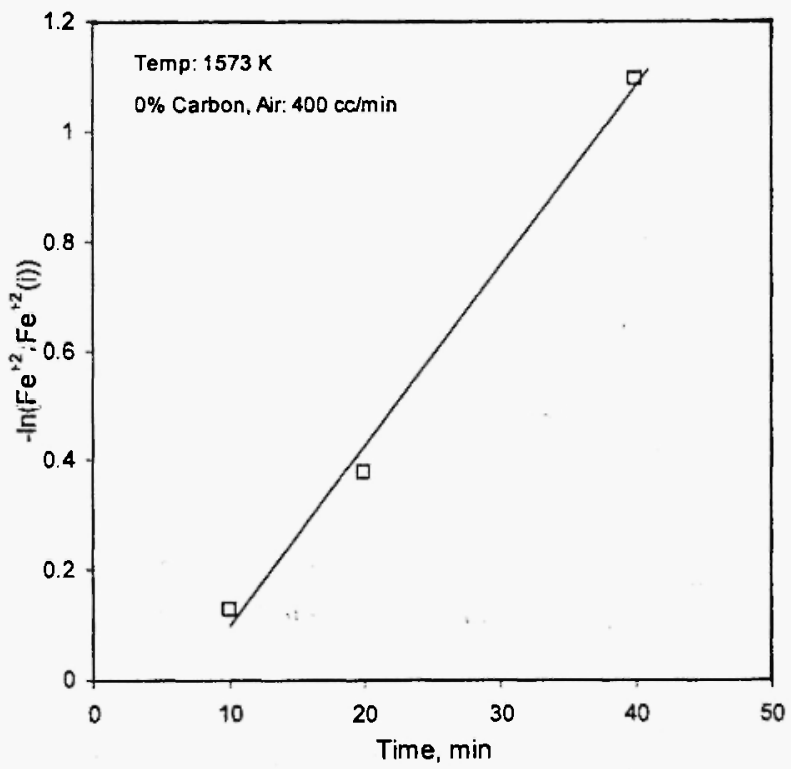

Fig. 8: Diffusion controlled model for $\mathrm{ZnO}$ reduction in melts containing $0 \%$ carbon and air as the stirring gas at a flow rate of $400 \mathrm{cc} / \mathrm{min}$. 
rate of $400 \mathrm{cc} / \mathrm{min}$ and with no carbon in the melt. The linearity of the plot indicates clearly that the rate controlling mechanism was indeed the diffusion of $\mathrm{Fe}^{+2}$ ions in the slag.

Figure 9 shows a plot of the left hand side term of equation (11) (chemical reaction model) as a function of time for experiments shown in Fig. 5. The linearity for all the three experiments very clearly indicates that in slags containing carbon as an external reducing agent, reduction of $\mathrm{ZnO}$ was essentially due to the chemical reaction at the slag/gas interface. However, at a higher flow rate $(300 \mathrm{cc} / \mathrm{min})$ of argon a change of slope was observed at about 20 minutes. The change in slope indicates a change in the reaction rate constant but the basic mechanism of $\mathrm{ZnO}$ reduction essentially remains the same.

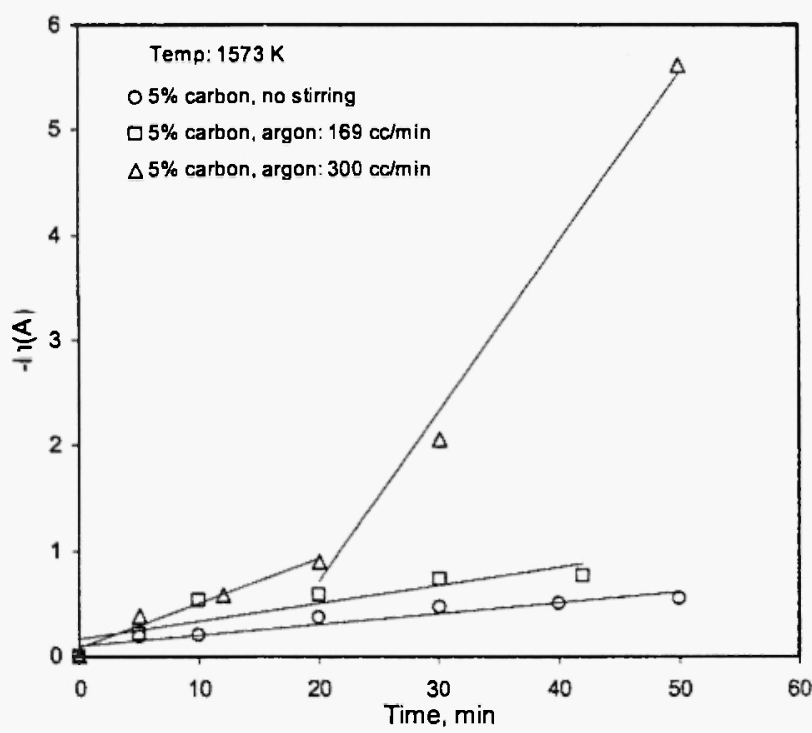

Fig. 9: A plot of chemical reaction model [equation (11)] for different experimental conditions, where $\mathrm{A}$ is given by $\left(\frac{\% \mathrm{ZnO}^{\mathrm{t}}-\% \mathrm{ZnO}^{\mathrm{e}}}{\% \mathrm{ZnO}^{\mathrm{i}}-\% \mathrm{ZnO}^{\mathrm{e}}}\right)$.

Figures 10 and 11 show the comparison of the two models for the experiment conducted with $5 \%$ carbon and air at a flow rate of $375 \mathrm{cc} / \mathrm{min}$ and $12 \%$ carbon and air at a flow rate of $650 \mathrm{cc} / \mathrm{min}$ respectively. The figure clearly shows that in both cases chemical reaction at the slag/gas interface was indeed the rate controlling mechanism for $\mathrm{ZnO}$ reduction in the lead blast furnace slag.

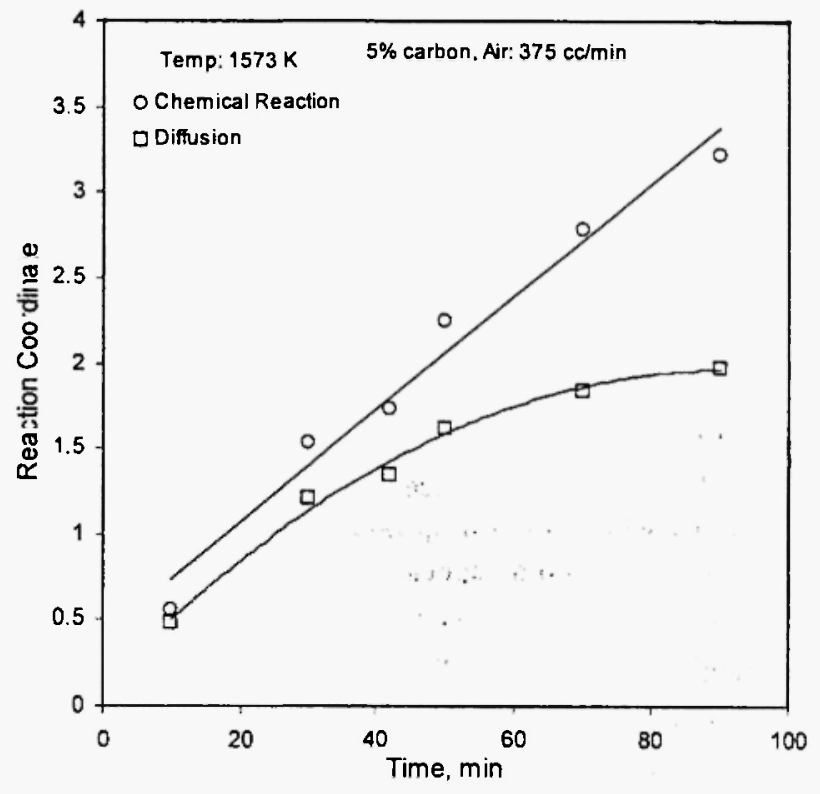

Fig. 10: Comparison of the two models for the reduction of $\mathrm{ZnO}$ in slags containing $5 \%$ carbon and air at a flow rate of $375 \mathrm{cc} / \mathrm{min}$. Left hand side terms of equations (11) and (14) are plotted as a function of time.

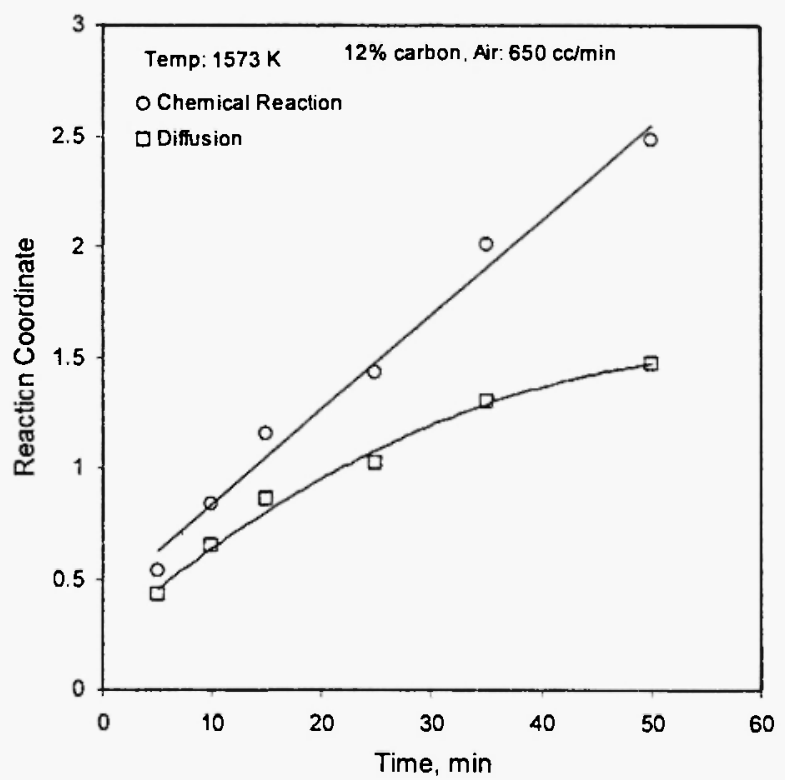

Fig. 11: Comparison of the two models for the reduction of $\mathrm{ZnO}$ in slags containing $5 \%$ carbon and air at a flow rate of $650 \mathrm{cc} / \mathrm{min}$. Left hand side terms of equations (11) and (14) are plotted as a function of time. 
Since the isothermal experiments have been carried out the temperature effect on the reduction of $\mathrm{ZnO}$ could not be determined. However, increase in temperature would ideally ascertain whether or not the reaction was controlled by the chemical reaction at the gas-slag interface. In the present investigation we found that an increase in flow rate of the stirring gas did not influence the reaction mechanism (chemical reaction controlled) except that the rate of reaction was faster.

Figure 12 shows the variation of the amount of $\mathrm{ZnO}$ in the lead blast furnace slag as a function of slag tapping temperature from recent industrial data /9/. Our experimental point appears well within the band of a recent industrial data on zinc recovery from metallurgical wastes by the Enviroplas process /9/ for approximately similar conditions. It was reported that $\mathrm{ZnO}$ present in the lead blast furnace slag decreased from $13 \mathrm{wt} \%$ to $2 \mathrm{wt} \%$ as a function of slag tapping temperature in the range of 1500-1823 K. Coke addition to the melt was $4 \mathrm{wt} \%$ and the slag basicity $\left(\mathrm{CaO}+\mathrm{MgO} / \mathrm{SiO}_{2}\right)$ was 0.8 . At $1573 \mathrm{~K}$ their data varied between $6-8 \mathrm{wt} \% \mathrm{ZnO}$ in slag. Our results indicate that for a slag of basicity 0.75 , containing $5 \mathrm{wt} \%$ carbon with no stirring, the amount of $\mathrm{ZnO}$ present at $1573 \mathrm{~K}$ was $7.4 \mathrm{wt} \%$, which is in excellent agreement with the reported experimental data.

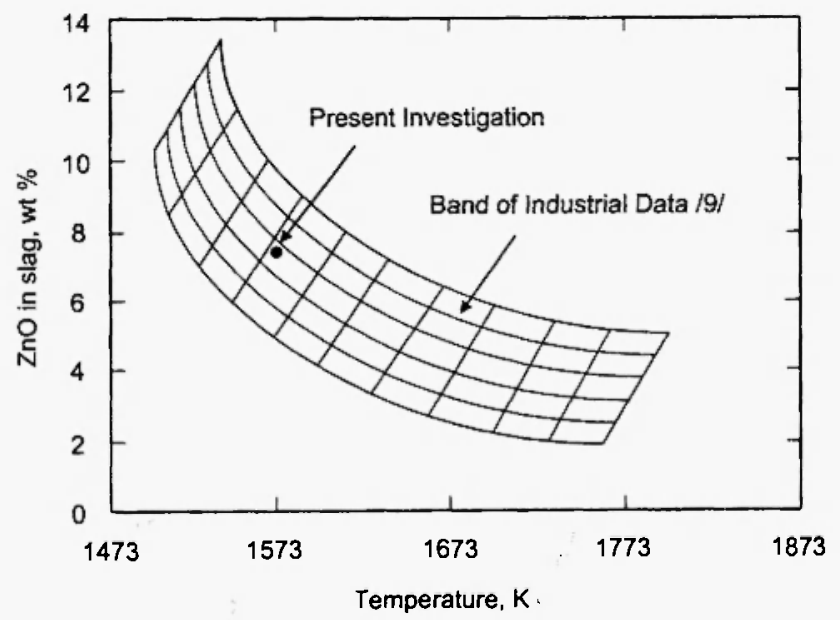

Fig. 12: Comparison of $\mathrm{ZnO}$ content in the slag at $1573 \mathrm{~K}$ from the present investigation with a band of recent industrial data $/ 9 /$.

\section{CONCLUSIONS}

The present investigation deals with the analysis of the zinc fuming process from a lead blast furnace slag based on laboratory scale experiments. The influence of various parameters such as carbon addition, the type and flow rate of external stirring gas on the zinc fuming rate was studied. Stirring the melt improved the rate of $\mathrm{ZnO}$ reduction even in the absence of any reducing agent due to $\mathrm{FeO}$ present in the slag. In melts containing no carbon, reduction of $\mathrm{ZnO}$ took place by diffusion of the $\mathrm{Fe}^{+2}$ ions in the slag melt. Chemical reaction at the slag/gas interface was the rate controlling mechanism of $\mathrm{ZnO}$ reduction in melts containing carbon as an external reducing agent irrespective of the type of gas and its flow rate used in stirring the melt. Results of this investigation concur with those reported in the literature on zinc fuming from lead blast furnace slags.

\section{ACKNOWLEDGEMENTS}

The authors are pleased to acknowledge the financial support of American Cast Iron Pipe Company (ACIPCO) for conducting this research.

\section{REFERENCES}

I. G. Courtney, New Series, Australasian Institute of Mining and Metallurgy, 38, 75-84 (1920).

2. R.C. Bell, G.H. Turner and E. Peters, J. Metals Trans AIME, 203, 472-477 (1955).

3. H.H. Kellogg, Trans. Metall. Soc. AIME, 239, 1439 1449 (1967).

4. H.H. Kellogg, Engg \& Mining J., 158 (3), 90-92 (1957).

5. T.A.A. Quarm, Mining Magazine, 113 (2), 114-121 (1965).

6. G.G. Richards, J.K. Brimacombe and G.W. Toop, Metall. Mater. Trans., 16B, 513-527 (1985).

7. A. Deneys, D. Robertson and N. Schupp, EPD Congress 1997, B. Mishra (Ed.), TMS, Warrendale, PA, 621-633 (1997).

8. W.J. Rankin and S. Wright, Metall. Mater. Trans., 21B, 885-897 (1990).

9. M.A. Abdel-latif, Minerals Engg., 15, $945-952$ (2002). 